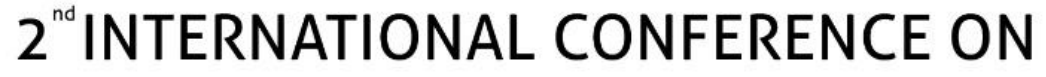 FUTURE OF TEACHING \& EDUCATION
}

Munich,Germany

6 - 8 December,2019

\section{New mobile applications in the benefit of students with verbal disabilities}

\author{
Emilia-Maria Sorescu $^{1 *}$ and Gabriela-Eugenia Iacobescu ${ }^{2}$, \\ ${ }^{1}$ Faculty of Social Sciences, University of Craiova, Romania \\ ${ }^{2}$ Faculty of Sciences, University of Craiova, Romania
}

\begin{abstract}
.
This paper reports the results of two ERASMUS+ projects which aimed to design and develop mobile applications for the benefit of disadvantaged groups. The aim of the first project was the creation of digital learning resources for mobile devices to improve the educational integration of disadvantaged learners in the educational system - groups in risk whose ethnocultural characteristics, special needs or socioeconomic status significantly restrict their ability for adequate education. The second project focused on social integration of people with verbal communication disorders that are at risk of social isolation by using mobile devices adapted to their needs. The research started with a systematic needs analyses in order to understand the basic characteristics of the target groups and to prepare its pedagogicalpsychological profile. This helped us build a conceptual model, corresponding to the skills, knowledge, competence, abilities and specific needs of the group, for which the digital resources for learning and communicating would be developed. The outcomes of the projects were two different adaptive and personalized software tools and two large databases with images and videos designed by educators and tutors and shared by the project community. Pilot stages confirmed the usefulness and the consistency of the new mobile applications for the specific kind of disadvantaged groups.
\end{abstract}

Keywords: m-learning, social inclusion, software application, European projects.

\section{Introduction}

Today the use of mobile technologies is mostly in the sphere of services and entertainment and very limited in education and work, despite the fact that the literature mentioned a lot of innovative mobile learning initiatives, from the preschool to higher education (Clarke, 2015, ICF, 2015, Wu et al. 2012, Sung et al., 2016), and even special education (Allen et al., 2016, De Leo et al., 2011, Draper Rodríguez \& Cumming, 2017, Ismaili \& Ibrahimi, 2017). The teaching areas in which $\mathrm{m}$ learning was used are very diverse: foreign languages, mathematics and science, medicine etc. In 2012 and 2013 with UNESCO support was publish 14 papers: six papers examine mobile learning initiatives and their policy implications, and six papers examine how mobile technologies can support teachers and improve their practice; one paper highlights characteristics shared by successful mobile learning initiatives and identifies 


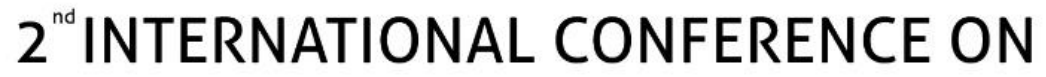 FUTURE OF TEACHING \& EDUCATION}

\section{Munich,Germany}

\section{6 - 8 December,2019}

supportive policies and the last paper discusses how mobile technologies are likely to impact education in the future. (Shuler et. al, 2012).

On the other hand, almost every active person has at least one mobile device, thus they can be the only technology used in education which does not require additional investment in infrastructure. Mobile technologies give freedom to both teachers for complex presentation, and to students for extended study of a considered problem in accordance with their educational needs, which, according to the constructivist views, is a condition for manifestation of independence and initiative. Students can use these technologies both in the classroom and out of it in convenient time, and they can access a wealth of informational resources. The use of these technologies does not require from the students a preparation in advance. The interactive multimedia products are usually complied to their intuitive perceptions and their personal preferences and offer very good possibilities for building up steady interest and lasting motivation (Dunn \& Kennedy, 2019), but also supporting independent learning, and promoting engaging teaching methods (Rikala et al. 2013). Taking into account the benefits of m-learning it is necessary to introduce technical and pedagogical support in order to facilitate both teachers' and students' understanding of the full potential of this kind of technology in education. (Montrieux et al. 2015)

For the people with disabilities, the mobile technologies are increasingly used, and it is an area in which this type of IT can have a very substantially contribution at the quality of life and the social integration of this vulnerable group. (UNESCO, 2013)

Based on these considerations, academic institutions and secondary schools from Bulgaria, Romania, Spain, United Kingdom, Greece, Poland, and Croatia cooperated in two ERASMUS+ Key Action 3: Support for policy reform - Social inclusion through education, training and youth, having as main objective the use of mobile devices for interacting with disadvantaged population.

The first project (2016-2018) "mRIDGE - Using mobile technology to improve policy Reform for Inclusion of Disadvantaged Groups in Education" focused on the design of new applications for mobile technologies for stimulation, support and for implementing innovations in the education of the following disadvantaged groups: Roma children and their teachers, hearing impaired children and their teachers, people with musculoskeletal disorders, unemployed people.

The second project (2017-2019) "TESI - Adaptive Personalized System for Creating Expression Tools in Social Inclusion of Learners with Verbal Communication Disabilities" studied the use of mobile technology for social integration of people with verbal communication disorders who are at risk of social isolation. The main beneficiaries of TESI project are: people with verbal communication disabilities; teachers, tutors, (special) educators; caregivers; parents; supportive staff; nurses; psychologists; social educators, social workers. In a long-term, the results of the projects will be useful for: counsellors /coaches/mentors (in a broad sense) (for those who have a bachelor's and / or master's degree in psychology, pedagogy, medicine, sports, social activities and want to further develop in this area); authorities, policy makers in the area of special education; management of educational institutions; community members. 


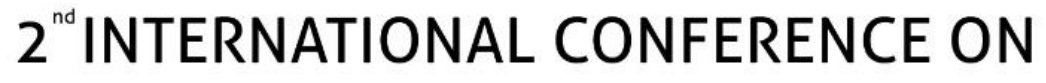 FUTURE OF TEACHING \& EDUCATION}

\section{Munich,Germany}

\section{6 - 8 December,2019}

\section{Methods}

In order to identify the needs of using mobile technologies in learning/ teaching process for high school students and teachers, academic students and professors, we gathered information from 228 questionnaires and 68 interviews, in the frame of mRIDGE project.

From the analysis of the data provided from the students' questionnaire, we can draw the following conclusions:

1. Most students are skilful in using the mobile technologies/ devices.

2. The students make efforts to learn.

3. They are interested in studying with the help of mobile technologies/ devices in class or at home due to quick access to information.

4. They would learn easier with the help of mobile technologies.

5. They could help the others more easily when using mobile technologies.

6. They consider that they would have more fun if they were using mobile technologies for learning.

7. They would like to interact with their colleagues and teachers during their free time, outside the school, by using mobile technologies.

8. They would like to assist classes consisting of video presentations.

From the analysis of the data provided by the teachers' questionnaire, we can draw the following conclusions:

1. Learning with the help of mobile technologies can prove itself as being an effective method of learning as it can provide immediate support for disabled students.

2. Learning with the help of mobile technologies brings new opportunities of learning for disabled students due to the fact that visual and audio images have a greater impact on them.

3. Learning with the help of mobile technologies is a more flexible method of learning if we take into account the fact that it can take place under all circumstances, regardless of time and place.

4. Learning with the help of mobile technologies improves communication between the student and the teacher.

5. Learning with the help of mobile technologies is a quicker method of getting an immediate feedback from students.

6. Learning with the help of mobile technologies can be used in one of the following cases:

a) When the mobile phones are available even if the number of students increases.

b) When the expenses involved in the process are lower.

c) When there is good internet network in the school.

7. It is not difficult to control the use of cell phones/laptops/tablets in class 


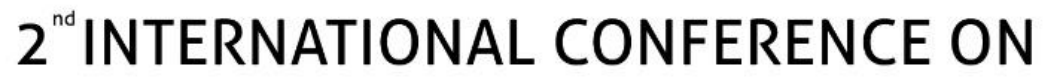 FUTURE OF TEACHING \& EDUCATION}

\section{Munich,Germany}

\section{6 - 8 December,2019}

8. Students need a classroom experience that is creative and challenging.

Based on these results the mobile application should make the access easier during teaching classes to a specific database with education tools (images, videos) built by teachers in order to adapt the content to each student's characteristic [1-2].

In the case of TESI project, for all students from the target groups there were identified areas of communications to be improved on for a better social integration: hygiene, nourishment, dressing, playing with other children, health, shopping, moving around familiar environment, public transportation, communication with neighbours, communication with unfamiliar people, expressing personal needs and wants, social interactions.

Taking into consideration the student's status and needs, TESI Tool was designed as an assistive communication tool which enabled users to communicate using visual cues (images) and to learn and perform daily activities by following visual instructions. A database of images collected by teachers and parents was made, in order to fit the specific needs of each student, after the general needs were taken into consideration in the application design [3].

We can divide the students' needs in two main classes:

1. Needs which require direct communication of users (people with verbal difficulties) with carers/tutors using mobile technology: nourishment, playing with other children, moving around familiar environment, public transportation, communication with neighbours, communication with unfamiliar people, expressing personal needs and wants, social interactions, etc.

2. Needs which can be solved by direct use of the mobile technology: hygiene, dressing, orientation in space, etc.

Some areas, as health, can be considered in both categories.

For the first category of needs, it was necessary to develop a software which allows both parts (users and tutors) to have a dialogue using the image library from the tablets. The image library is individually designed for each user, by the carers (teachers, parents, etc.) and can be shared in the community of the project target groups.

We call this category of TESI tool: Expressions, with two approaches: Users' expressions and Carers expressions'. For the users' expression tool, we took into consideration the status of the students. The images should be relevant for each user and easy to access. We found that some parts of the software are better in an adaptive form, as the tutor sees fit (images access, dimensions, position on the screen, etc.)

The second category of TESI tools consists in sequences of images which will show users "how to do" daily routines: how to dress, how to wash, etc. In addition to the relevance of images composing the instruction, the carer will decide upon the succession of images (on pushing/scrolling, automatic) 


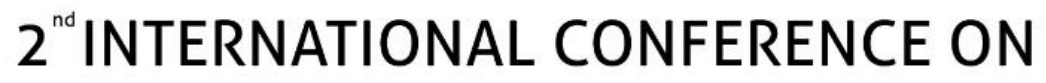 FUTURE OF TEACHING \& EDUCATION}

\section{Munich,Germany}

\section{6 - 8 December,2019}

\section{Results and Discussion}

The mobile applications work on tablets and convertible devices with a touch-screen, running operating systems Android, iOS and Windows.

The web-based applications use the latest versions of browsers Google Chrome, Apple Safari, Microsoft Edge and Internet Explorer, but are also able to work on older versions if needed - some users may not have modern and updated hardware.

- mRIGDE tool is used only by educators during teaching as follows [4]:

- Teachers prepare additional images and/or videos for a specific topics, adapted to each student needs and make a lesson database;

- Using mRIDGE applications he/she assigns a QR code to each database object;

- During the teaching process, teacher distributes these codes to students and ask them to apply mRIDGE application installed on their tablets to access the image/video as additional explanation, specific for the student need (Fig. 1);

- The student can choose by himself, or advised by the teacher, how many times he wants to access the tool, or if he/she need extra-tools.

- TESI tool is organized as two applications [5]:

- One of them is used by both tutors (teachers, parents) and students/children as a "dialog" by means of tablets, accessing images which depict the intentions and needs (Fig. 2);

- In addition to teachers, parents can also contribute to collect the proper images for the database, specific for each child;

- The second applications allows the child to access a succession of instructions, already designed by tutors, for manage simple actions in real life (Fig.3). 


\section{$2^{\text {nd }}$ INTERNATIONAL CONFERENCE ON FUTURE OF TEACHING \& EDUCATION}

\section{Munich,Germany}

\section{6 - 8 December,2019}
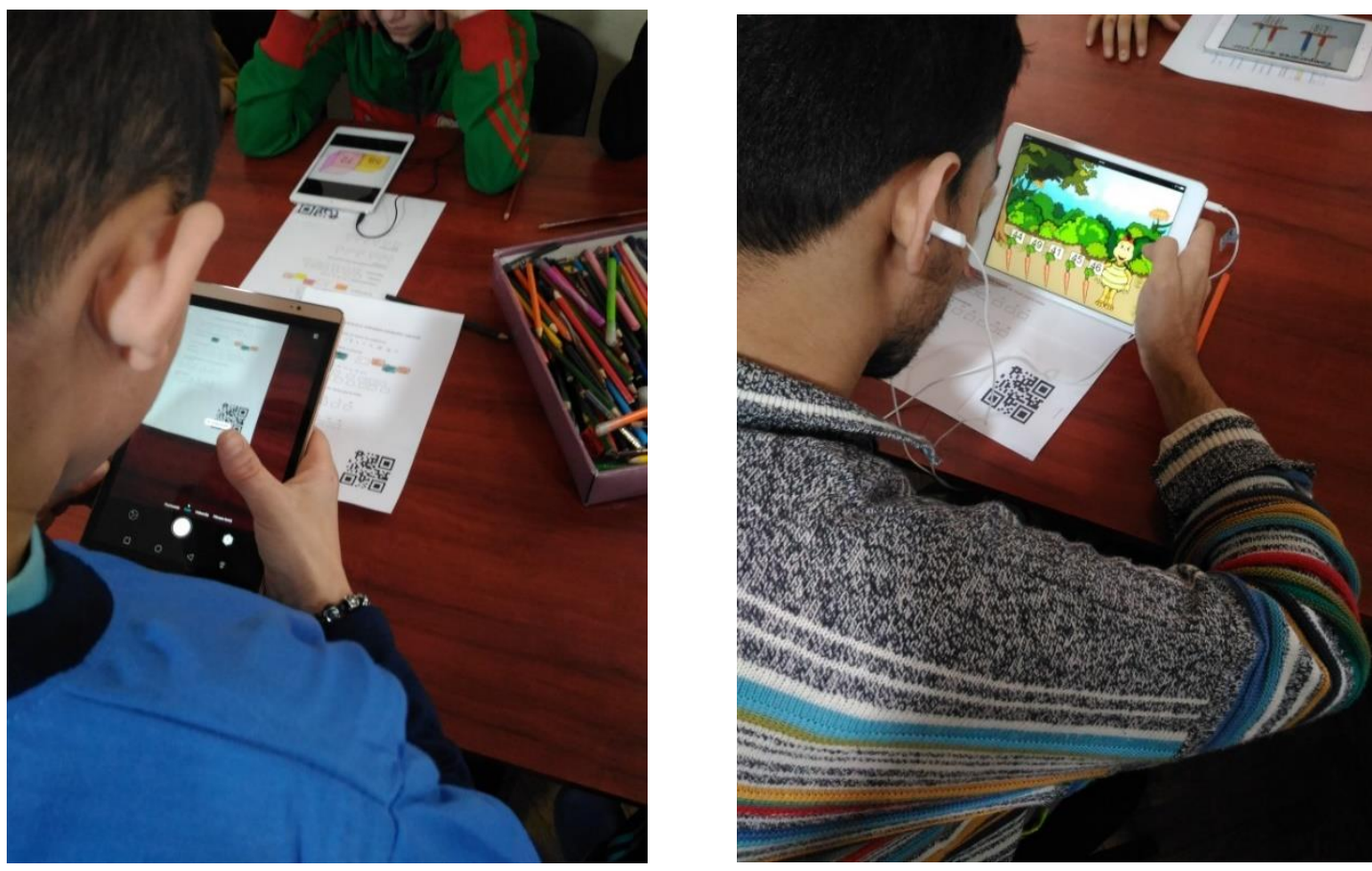

Fig. 1. Using QR codes reader (mRIDGE tool) application during lessons.

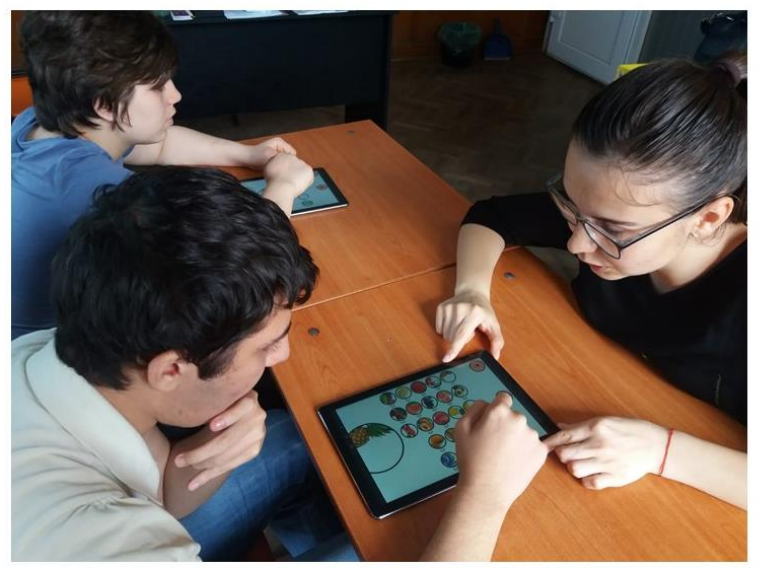

Learning objectives:

1.Recognizing fruits.

2.Practicing

pronunciation.

3. Practicing expressing

his food preferences.

The picture sequence

includes fruits.

The student asks the child to show the fruit

'pineapple' and the child

choses the fruit and

repeats its name.

Fig. 2. TESI tool for communication. 


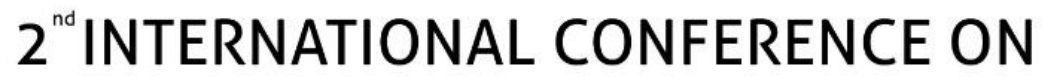 FUTURE OF TEACHING \& EDUCATION
}

\section{Munich,Germany}

\section{6 - 8 December,2019}

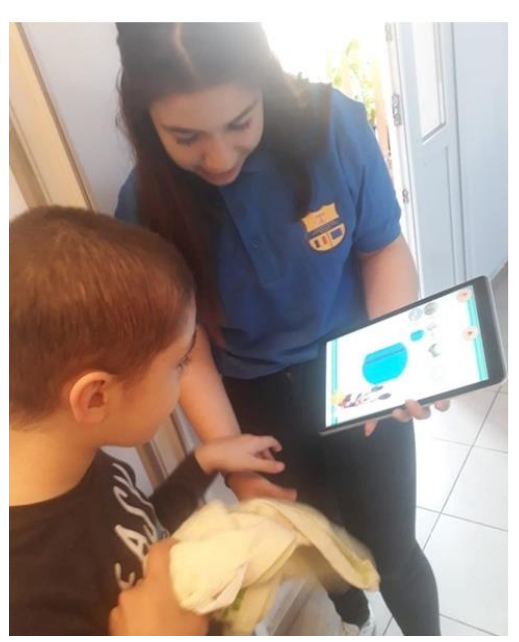

\author{
Learning objectives: \\ 1. Expressing needs. \\ 2. Strengthening personal \\ hygiene skills. \\ The picture sequence shows \\ personal hygiene related \\ activities. \\ After learning the proper way to \\ wash his hands, the tablet \\ shows Edi the last step, which is \\ taking the towel and drying his \\ hands.
}

Fig. 3. TESI instruction sequences for everyday routines.

\section{Conclusion}

New software tools were designed in order to fulfil the needs of some disadvantaged groups for a better education and social inclusion. The software consists of applications for mobile devices customized so that they can be used by people with physical and mental impairments, but also to improve communication in non-integrated communities, such as refugees. Both applications have key features of TESI Tool as accessibility, adaptability, extensibility and sharing. They were successfully piloted in schools and specific organizations, and the results are very promising.

\section{Acknowledgment}

This paper is an output of the ERASMUS+ KA3 Project: Adaptive Personalized System for Creating Expression Tools in Social Inclusion of Learners with Verbal Communication Disabilities - TESI, No. 592177-EPP-1-2017-1-BG-EPPKA3-IPI-SOC-IN.

\section{References}

[1] Allen ML, Hartley C and Cain K (2016) iPads and the Use of "Apps" by Children with Autism Spectrum Disorder: Do They Promote Learning?. Frontiers in Psychology 7:1305.

[2] Archer, K., Savage, R., et al. (2014). 'Examining the effectiveness of technology use in classrooms: A tertiary meta-analysis.' Computers \& Education: an international journal. VOL. 78, 140-149

[3] Bryant DP, Erin J, Lock R, Allan JM \& Resta PE (1998). Infusing a Teacher Preparation Program in Learning Disabilities with Assistive Technology. Journal of Learning Disabilities. 31(1): 55-66.

[4] Clarke, B., \& Svanaes, S. (2015). Updated review of the global use of mobile technology in education. London: Techknowledge for Schools. Available at: 


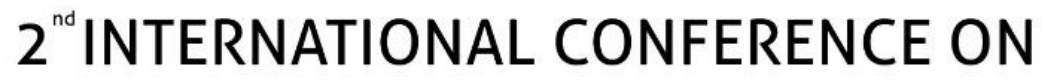 FUTURE OF TEACHING \& EDUCATION}

\section{Munich,Germany}

\section{6 - 8 December,2019}

http://www.kidsandyouth.com/pdf/T4S\%20FK\%26Y\%20Literature\%20Review\%2011.12 15.pdf

[5] De Leo G., Gonzales CH, Battagiri P et al. (2011) A Smart-Phone Application and a Companion Website for the Improvement of the Communication Skills of Children with Autism: Clinical Rationale, Technical Development and Preliminary Results, Journal of Medical Sistems, 35: 703.

[6] Draper Rodriguez C \& Cumming TM (2016) Employing mobile technology to improve language skills of young students with language-based disabilities. Assistive Technology 29(3): 161-169

[7] Dunn TJ, Kennedy M (2019) Technology Enhanced Learning in higher education; motivations, engagement and academic achievement. Computers and Education 137: 104137

[8] Iacobescu, G. E. (2016). Needs for mobile technology to expand training opportunities of people with musculoskeletal disorders, The 9th annual International Conference of Education, Research and Innovation - ICERI2016, Seville, Spain,

[9] Iacobescu, G. E. (2017). Using mobile technology to improve policy reform for inclusion of disadvantaged groups in education - mRIDGE project, The Future of Education Conference, Florence, Italy,

[10] Iacobescu, G. E., Pavlov, N. V. (2019). TESI model - Assistive communication tool for people with reading, writing and verbal communication difficulties, INTED2019, Valencia, Spain,

[11] Iacobescu, G. E. (2017). M-learning tools for disadvantages students - mRIDGE project, International Conference on Education and New Developments 2017 (END 2017), Lisbon, Portugal,

[12] Iacobescu, G. E. (2019). TESI - mobile application for education and social inclusion of people with communication difficulties, The 12th annual International Conference of Education, Research and Innovation - ICERI2019, Seville, Spain

[13] ICF Consulting Services (2015). Literature review on the impact of digital technology on learning and teaching. Edinburgh: The Scottish Government Publications.

[14] Montrieux, H., Vanderlinde, R., Schellens, T., \& De Marez, L. (2015). Teaching and Learning with Mobile Technology: A Qualitative Explorative Study about the Introduction of Tablet Devices in Secondary Education. PloS one, 10(12), e0144008. doi:10.1371/journal.pone.0144008

[15] Rikala, J. \& Vesisenaho, M. \& Mylläri, J. (2013). Actual and Potential Pedagogical Use of Tablets in Schools. Human Technology: An Interdisciplinary Journal on Humans in ICT Environments. 9. 113-131.

[16] Shuler, C., Winters, N., \& West, M. (2012). The future of mobile learning: Implications for policy makers and planners. Paris: UNESCO 


\section{Munich,Germany}

\section{6 - 8 December,2019}

[17] Sung, Y.-T., Chang, K.-E., \& Liu, T.-C. (2016). The effects of integrating mobile devices with teaching and learning on students' learning performance: A meta-analysis and research synthesis. Computers \& Education 94: 252-275.

[18] UNESCO (2013) Policy guidelines for mobile learning. Paris: UNESCO. Available at https://unesdoc.unesco.org/ark:/48223/pf0000219641.

[19] Wu W-H, Jim Wu Y-C, Chen C-Y, Kao H-Y, Lin C-H \& Huang S-H (2012) Review of trends from mobile learning studies: A meta-analysis. Computers \& Education 59(2): 817-827. 